\title{
Intradural, extramedullary hemangioblastoma at the level of the conus medullaris: illustrative case
}

\author{
Lisa B. E. Shields, MD, ${ }^{1}$ John E. Harpring, MD, ${ }^{1}$ Hilary A. Highfield, MD, PhD, ${ }^{2}$ Yi Ping Zhang, MD, ${ }^{1}$ and Christopher B. Shields, $M D^{1,3}$ \\ ${ }^{1}$ Norton Neuroscience Institute and ${ }^{2}$ CPA Laboratory, Norton Healthcare, Louisville, Kentucky; and ${ }^{3}$ Department of Neurological Surgery, University of Louisville School of \\ Medicine, Louisville, Kentucky
}

\begin{abstract}
BACKGROUND Hemangioblastomas are rare, slow-growing, and highly vascularized tumors that typically occur in the cerebellum and spinal cord. The cervical and thoracic regions are the most common spinal sites, and the tumors are usually intramedullary.

OBSERVATIONS The authors report the case of a man whose chest computed tomography performed for managing coronavirus disease 2019 incidentally revealed an enhancing area in the spinal canal at T12-L1. The patient reported low back pain as well as leg numbness and tingling. Magnetic resonance imaging of the lumbar region with and without gadolinium contrast demonstrated an intradural, extramedullary lesion with displacement of the conus medullaris. The differential diagnosis included a schwannoma and myxopapillary ependymoma. Bilateral T12-L1 laminectomies were performed with resection of the mass. The general pathologist rendered the frozen section diagnosis of a spindle cell neoplasm, suggesting the differential diagnosis of schwannoma or myxopapillary ependymoma. Immunohistochemistry was positive for inhibin, GFAP, reticulin, CD31, SOX-10, S100, and EMA. A World Health Organization grade 1 hemangioblastoma was confirmed.
\end{abstract}

LESSONS Spinal surgeons should be cognizant of the presenting symptoms and differential diagnosis of hemangioblastomas at the level of the conus medullaris, especially when the tumor is diagnosed incidentally. Additional investigations should be performed to determine whether von Hippel-Lindau syndrome is associated with the hemangioblastoma, as this combination portends a different clinical presentation, multiple tumor locations, and tumor recurrence following resection.

https://thejns.org/doi/abs/10.3171/CASE2145

KEYWORDS neurosurgery; hemangioblastoma; conus medullaris; intradural; extramedullary

Hemangioblastomas are vascular neoplasms that account for $1 \%-3 \%$ of all central nervous system (CNS) tumors and are usually present in the cerebellum, brainstem, or spinal cord. ${ }^{1-4}$ Although the majority of spinal hemangioblastomas are located in the cervical and thoracic regions, ${ }^{1,5-13}$ they have also been reported in the lumbar and sacral spine, ${ }^{5}$ cauda equina, ${ }^{2,14,15}$ and filum terminale. ${ }^{16,17}$ Few cases have been described $i^{18-24}$ or at the level of ${ }^{25-27}$ the conus medullaris.

Most spinal hemangioblastomas are isolated intramedullary tumors. $^{2,7,28,29}$ A total of $70 \%-80 \%$ of spinal cord lesions arise sporadically, whereas the remainder are associated with von Hippel-Lindau syndrome. . $^{1,11,30}$ von Hippel-Lindau syndrome is a tumor suppressor gene syndrome marked by mutations in the VHL gene in the chromosome $3 p 25-26$ region. ${ }^{10,30}$ It is transmitted in an auto- somal dominant manner and is associated with several pathological conditions, including CNS tumors (hemangioblastomas, retinal angiomatosis, endolymphatic sac tumors), renal cell carcinoma/cysts, pancreatic carcinomas/cysts, pheochromocytomas, and epididymal cystadenomas. ${ }^{5,31,32}$ When spinal hemangioblastomas occur without von Hippel-Lindau syndrome, the tumors are usually sporadic and isolated, rarely recur following surgical resection, and are associated with more severe neurological deficits. ${ }^{1,33}$

Herein, we present the unique case of an intradural, extramedullary hemangioblastoma at the level of the conus medullaris that was discovered incidentally on a chest computed tomography (CT) scan. We describe the diagnosis, surgical treatment, and prognosis for this rare tumor. The differential diagnosis and investigation for von Hippel-Lindau syndrome are also discussed.

ABBREVIATIONS CNS = central nervous system; CT = computed tomography; MRI = magnetic resonance imaging

INCLUDE WHEN CITING Published April 26, 2021; DOI: 10.3171/CASE2145.

SUBMITTED January 20, 2021. ACCEPTED February 3, 2021.

(C) 2021 The authors, CC BY-NC-ND 4.0 (http://creativecommons.org/licenses/by-nc-nd/4.0/). 


\section{Illustrative Case}

\section{History and Radiological Imaging}

A 65-year-old man (body mass index: $31.14 \mathrm{~kg} / \mathrm{m}^{2}$ ) was hospitalized in the intensive care unit for 4 days with bilateral pneumonia after testing positive for coronavirus disease 2019. The patient reported occasional low back pain as well as numbness and tingling of his legs. He denied weakness of the lower extremities and had no bowel or bladder abnormalities. Within 1 week after discharge, a chest CT scan revealed incidental evidence of a 1.3-cm rounded area of enhancement in the spinal canal at T12-L1. Magnetic resonance imaging (MRI) of the lumbar region with and without gadolinium contrast demonstrated a well-defined, homogeneous, enhancing, intradural, extramedullary lesion within the left side of the spinal canal at T12-L1 with displacement of the conus medullaris from left to right and from anterior to posterior (Fig. 1). The mass measured $13 \mathrm{~mm}$ in axial diameter and $15 \mathrm{~mm}$ in length. There was no edema within the distal thoracic cord or conus medullaris. Foci of decreased signal and nonenhancement within the lesion as well as curvilinear and nodular enhancement along the distal thoracic spinal cord were observed. The latter finding may represent prominent intradural extramedullary vessels. The differential diagnosis included a schwannoma and myxopapillary ependymoma. Brain, cervical, and thoracic MRI with and without gadolinium contrast did not reveal any lesions that may suggest von Hippel-Lindau

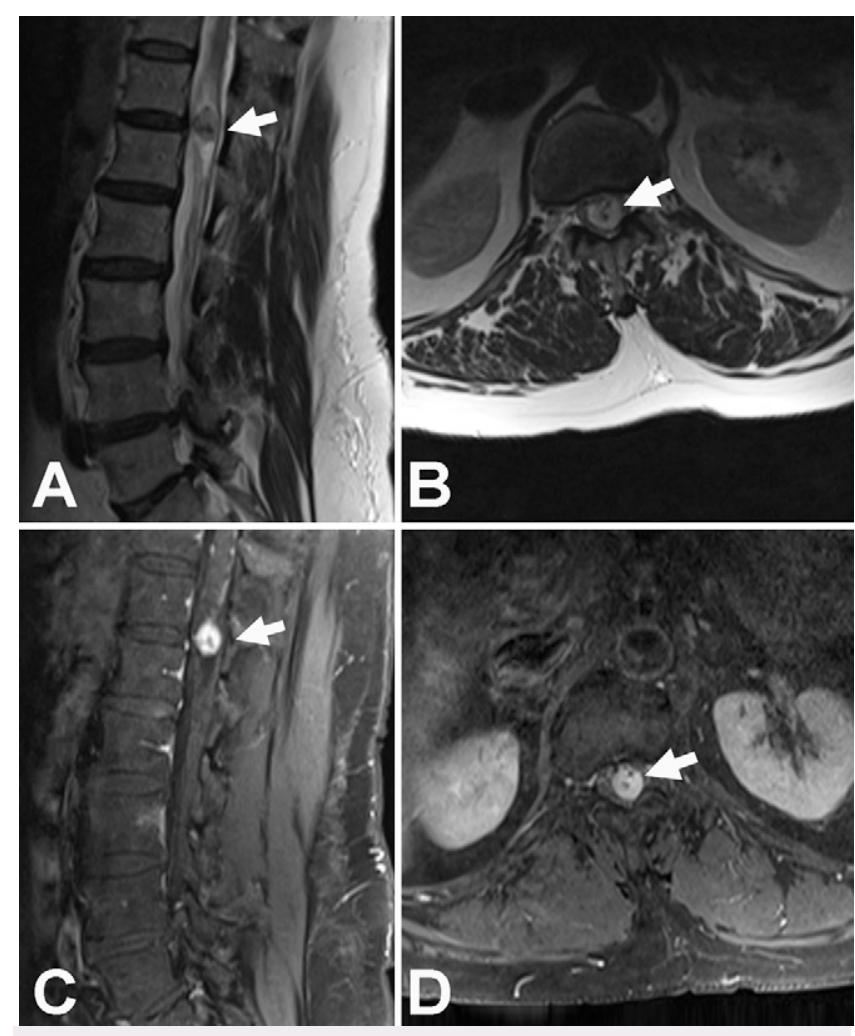

FIG. 1. Sagittal (A) and axial (B) MRI (T2) scans demonstrating an intradural, extramedullary mass at T12-L1 (arrows). High flow void vascular abnormalities can be seen within the tumor. Sagittal (C) and axial (D) gadolinium-enhanced T1-weighted fat-saturation MRI scans reveal the intradural, extramedullary mass displacing the conus medullaris from left to right (arrows).

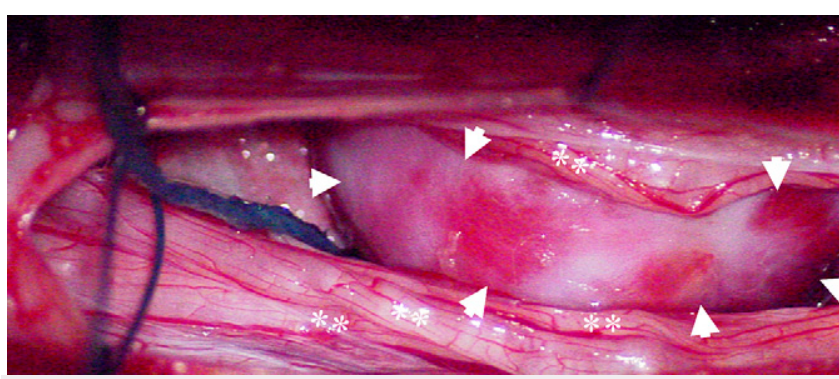

FIG. 2. Surgical photograph demonstrating the hemangioblastoma (arrowheads) severely displacing the nerves of the cauda equina (asterisks).

syndrome. An ophthalmoscopic evaluation did not reveal any ocular irregularities. Past medical history was significant for hypertension, hyperlipidemia, and osteoarthritis.

\section{Surgical Intervention}

Bilateral T12-L1 laminectomies were performed with gross-total resection of the intradural, extramedullary mass (Fig. 2). All of the nerve roots were dissected off of the tumor. The filum was thickened where the tumor was attached. The tumor was dissected off of the filum, and a small nerve entering the superior pole and exiting the inferior pole of the tumor was sectioned to obtain a grosstotal resection. The frozen section diagnosis provided by the general pathologist was a spindle cell neoplasm, suggesting the differential diagnosis of schwannoma or myxopapillary ependymoma.

\section{Histopathological Findings}

The tumor was hypervascular and contained vessels of varied sizes (Fig. 3A), including spindle-type cells with pleomorphic nuclei. The tumor stromal cells contained vacuolated cytoplasm (Fig. 3B) and were immunoreactive for inhibin (Fig. $3 \mathrm{C}$ ). Foci of extramedullary hematopoiesis were noted. GFAP labels surrounded the neuropil. Reticulin and CD31 highlighted the extensive vascular network within the tumor, and reticulin invested small groups of tumor cells. Scattered cells were immunoreactive for SOX-10, S100, and EMA. The Ki-67 proliferation index was low, labeling $<1 \%$ of tumor cell nuclei (Fig. 3D). A World Health Organization grade 1 hemangioblastoma was confirmed on permanent sections.

\section{Neurosurgical Follow-Up}

The patient did not undergo radiotherapy or chemotherapy following his surgical intervention. The numbness and tingling of his legs resolved within 2 weeks of his surgery.

\section{Discussion}

Although hemangioblastomas of or at the level of the conus medullaris are exceedingly rare, they have been reported more frequently in the intramedullary location. ${ }^{18-24}$ Following an extensive literature search, we encountered only 3 cases of intradural, extramedullary hemangioblastoma at the level of the conus medullaris (Table 1). ${ }^{25-27}$ The patient ages ranged between 33 and 57 years, and there were 2 women. All 3 patients reported back pain and either pain or dysesthesia of the legs preoperatively. A total resection of the tumor was performed in all 3 

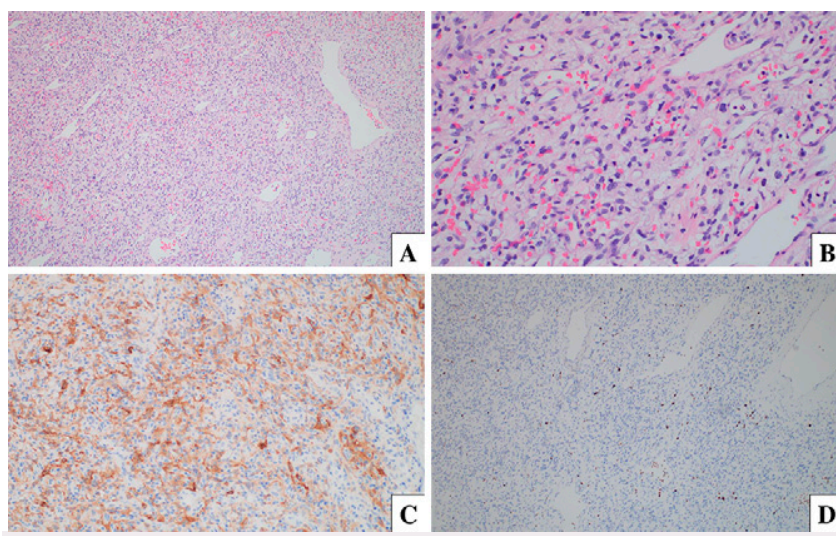

FIG. 3. A: Hematoxylin and eosin (H\&E) stain, original magnification $\times 100$. B: H\&E stain, original magnification $\times 400$. C: Inhibin immunohistochemistry, original magnification $\times 200$. D: Ki-67 immunohistochemistry, original magnification $\times 100$.

cases, and there was a complete resolution of the patients' symptoms postoperatively. No patients were diagnosed with von Hippel-Lindau syndrome. In Brisman and colleagues' case of intradural, extramedullary hemangioblastoma of the conus medullaris, myelography demonstrated prominent serpiginous filling defects. ${ }^{25}$ With a differential diagnosis of a radiculomeningeal (spinal dural) arteriovenous fistula or vascular tumor, the patient underwent selective spinal angiography before a T12-L1 bilateral laminectomy. Selective T11 angiography demonstrated a dense $1.0-\mathrm{cm}$ vascular blush posterior to the conus medullaris with a prominent posterior spinal artery feeder and radiculomedullary venous drainage.

Small spinal cord hemangioblastomas are usually asymptomatic until a syrinx develops that may be associated with tumor enlargement. ${ }^{30}$ Presenting symptoms often include pain and sensory disturbances of the legs in the early stages, and myelopathic-like symptoms such as hyperreflexia, urinary incontinence, and extremity weakness in more advanced cases. ${ }^{3,5}$ MRI with and without gadolinium contrast is the gold standard for diagnosing hemangioblastomas. On the enhanced T1-weighted images, bright enhancing and uniform lesions are observed, whereas T2-weighted images often reveal edema and a syrinx., ${ }^{3,5,11}$ The latter image has a greater diagnostic benefit, as it better delineates the vascular supply such as the presence of a vascular flow void shadow in or around the tumor body. ${ }^{3}$

When spinal hemangioblastomas are sporadic and isolated, they are usually curable following complete resection and have a low rate of recurrence. ${ }^{3,9}$ Recurrence may occur when the tumor is
TABLE 2. Differential diagnosis of spinal hemangioblastomas

\begin{tabular}{c}
\hline Enhancing neoplasms of the spinal cord \\
\hline Intradural, extramedullary tumors \\
\hline Spinal meningioma \\
\hline Myxopapillary ependymoma \\
\hline Leptomeningeal spinal metastases \\
\hline Neurogenic tumors \\
\hline Spinal schwannoma \\
\hline Spinal neurofibroma \\
\hline Spinal paraganglioma \\
\hline Intramedullary spinal cord tumors \\
\hline Spinal cord metastases \\
\hline Spinal astrocytoma \\
\hline Spinal ependymoma \\
\hline Vascular malformations of the spinal cord \\
\hline Spinal arteriovenous malformation \\
\hline Spinal dural arteriovenous fistula \\
\hline Spinal cavernous malformations \\
\hline
\end{tabular}

suboptimally resected or if the patient has von Hippel-Lindau syndrome. The prognosis is excellent for spinal hemangioblastomas postoperatively, with recovery rates greater than $96 \%{ }^{3}$

The differential diagnosis of spinal hemangioblastomas may pose a dilemma because of the myriad neoplasms and vascular malformations that share similar features (Table 2). ${ }^{34}$ Metastatic renal cell carcinomas should also be considered, especially in patients with von Hippel-Lindau syndrome. Selective spinal angiography may be beneficial in differentiating hemangioblastomas from vascular malformations and may be utilized to perform preoperative embolization to decrease bleeding during surgery. ${ }^{26,35}$ The defining elements of hemangioblastomas include marked enhancement and enlarged vessels.

\section{Observations}

The current case exemplifies a unique presentation of intradural, extramedullary hemangioblastoma at the level of the conus medullaris. Although the patient had a history of back pain and numbness and tingling of the legs, these symptoms did not precipitate a neurosurgical evaluation. Because this rare tumor was uncovered incidentally on a chest CT, it is imperative to pursue a thorough investigation to elucidate a spinal mass. This case was also perplexing with respect to the initial differential diagnoses. The findings of the preoperative lumbar MRI

TABLE 1. Intradural, extramedullary hemangioblastoma at the level of the conus medullaris in the literature

\begin{tabular}{lcccccc}
\hline \multicolumn{1}{c}{ Authors \& Yr } & $\begin{array}{c}\text { Age } \\
(\mathrm{yrs})\end{array}$ & Sex & Preoperative Symptoms & $\begin{array}{c}\text { von Hippel-Lindau } \\
\text { Syndrome }\end{array}$ & $\begin{array}{c}\text { Total } \\
\text { Resection of Tumor }\end{array}$ Resolution of Symptoms \\
\hline Brisman et al., $2000^{25}$ & 57 & F & Back pain, rt groin/thigh pain & No & Yes & Yes \\
\hline Dinc et al., $2006^{26}$ & 33 & F & Back pain, rt leg pain & No & Yes & Yes \\
\hline Welling et al., $2012^{27}$ & 43 & M & Back pain, dysesthesia of legs & No & Yes & Yes \\
\hline Present case & 65 & M & Back pain, numbness/tingling of legs & No & Yes & Yes \\
\hline
\end{tabular}


were consistent with a schwannoma and papillary ependymoma, whereas the intraoperative frozen section was suggestive of a schwannoma. The histopathological findings and immunohistochemistry subsequently and conclusively confirmed a hemangioblastoma. Although our patient was not diagnosed with von Hippel-Lindau syndrome, it is important to perform an ophthalmoscopic evaluation as well as brain and spinal MRI to rule out this syndrome.

\section{Lessons}

Spinal surgeons should be alert to the presenting symptoms and differential diagnosis of hemangioblastomas at the level of the conus medullaris, particularly in cases in which the tumor is diagnosed incidentally. Prompt complete resection of the hemangioblastoma is warranted before symptoms become severe. Although patients with sporadic and isolated tumors often do not experience a recurrence, continued monitoring is recommended. Determining whether von Hippel-Lindau syndrome accompanies the hemangioblastoma is imperative, as this combination is associated with a different clinical presentation, multiple tumor locations, and tumor recurrence following resection.

\section{Acknowledgments}

We acknowledge Norton Healthcare for their continued support.

\section{References}

1. Li Z, Curtis B, Layser R, et al. Intraosseous hemangioblastoma of the cervical spine: case report. J Neurosurg Spine. 2017;27(3):312-315.

2. Martins HO, Brock RS, Taricco MA, et al. Sporadic hemangioblastoma of cauda equina: an atypical case report. Surg Neurol Int. 2019; 10:60.

3. Wang $H$, Zhang $L$, Wang $H$, et al. Spinal hemangioblastoma: surgical procedures, outcomes and review of the literature. Acta Neurol Belg. Published online July 7, 2020. doi:10.1007/ s13760-020-01420-4

4. Westwick HJ, Giguère JF, Shamji MF. Incidence and prognosis of spinal hemangioblastoma: a Surveillance Epidemiology and End Results study. Neuroepidemiology. 2016;46(1):14-23.

5. Baker KB, Moran CJ, Wippold FJ II, et al. MR imaging of spinal hemangioblastoma. AJR Am J Roentgenol. 2000;174(2): 377-382.

6. Barbosa-Silva E, Carvalho GT, Frota MdeO, et al. Intradural extramedullary hemangioblastoma. Arq Neuropsiquiatr. 2009;67(2B): 530-533.

7. Browne TR, Adams RD, Roberson GH. Hemangioblastoma of the spinal cord. Review and report of five cases. Arch Neurol. 1976; 33(6):435-441.

8. Kitanaka C, Kuwahara M, Teraoka A. Intradural, purely extramedullary hemangioblastoma of the spinal cord-case report. Neurol Med Chir (Tokyo). 1993;33(6):377-380.

9. Li AY, Post AF, Dai JB, Choudhri TF. Spontaneous arrest of sporadic spinal hemangioblastoma growth after postoperative nodular recurrence: case report. Cureus. 2018;10(9):e3380.

10. Mehta GU, Montgomery BK, Maggio DM, et al. Functional outcome after resection of von Hippel-Lindau disease-associated cauda equina hemangioblastomas: an observational cohort study. Oper Neurosurg (Hagerstown). 2017;13(4):435-440.

11. Na JH, Kim HS, Eoh W, et al. Spinal cord hemangioblastoma: diagnosis and clinical outcome after surgical treatment. J Korean Neurosurg Soc. 2007;42(6):436-440.
12. Taniguchi S, Ogikubo O, Nakamura T, et al. A rare case of extramedullary-intradural hemangioblastoma in the thoracic spine. Spine (Phila Pa 1976). 2009;34(26):E969-E972.

13. Toyoda H, Seki M, Nakamura H, et al. Intradural extramedullary hemangioblastoma differentiated by MR images in the cervical spine: a case report and review of the literature. J Spinal Disord Tech. 2004;17(4):343-347.

14. Blaty D, Malos M, Palmrose T, McGirr S. Sporadic intradural extramedullary hemangioblastoma of the cauda equina: case report and literature review. World Neurosurg. 2018;109:436-441.

15. Kunihiro N, Takami T, Yamagata T, et al. Spinal hemangioblastoma of cauda equina origin not associated with von Hippel-Lindau syndrome-case report. Neurol Med Chir (Tokyo). 2011;51(10): 732-735.

16. Nadkarni TD, Menon RK, Desai KI, Goel A. Hemangioblastoma of the filum terminale. J Clin Neurosci. 2006;13(2):285-288.

17. Tucer B, Ekici MA, Kazanci B, Guclu B. Hemangioblastoma of the filum terminale associated with von Hippel-Lindau disease: a case report. Turk Neurosurg. 2013;23(5):672-675.

18. Alvarez R, Mastorakos P, Chittiboina P. Resection of a conus medullaris hemangioblastoma: case report. Interdiscip Neurosurg. 2021;23:100904.

19. Biondi A, Ricciardi GK, Faillot T, et al. Hemangioblastomas of the lower spinal region: report of four cases with preoperative embolization and review of the literature. AJNR Am J Neuroradiol. 2005; 26(4):936-945.

20. Boström A, Hans FJ, Reinacher PC, et al. Intramedullary hemangioblastomas: timing of surgery, microsurgical technique and followup in 23 patients. Eur Spine J. 2008;17(6):882-886.

21. Chen $\mathrm{CY}$, Chen $\mathrm{PH}, \mathrm{Yao} \mathrm{MS}$, et al. MRI of hemangioblastoma in the conus medullaris. Comput Med Imaging Graph. 2008;32(1): $78-81$.

22. Han $\mathrm{IH}$, Kuh SU, Chin DK, et al. Surgical treatment of primary spinal tumors in the conus medullaris. J Korean Neurosurg Soc. 2008; 44(2):72-77.

23. Michaud LJ, Jaffe KM, Benjamin DR, et al. Hemangioblastoma of the conus medullaris associated with cutaneous hemangioma. Pediatr Neurol. 1988;4(5):309-312.

24. Ya-juan T, Jie-wei B, Gui-huai W. Giant hemangioblastoma of the conus medullaris. Neurosurg Q. 2010;20:42-45.

25. Brisman JL, Borges LF, Ogilvy CS. Extramedullary hemangioblastoma of the conus medullaris. Acta Neurochir (Wien). 2000;142(9): 1059-1062.

26. Dinc C, Iplikcioglu AC, Ozcan D, et al. Spinal hemangioblastoma located in the conus medullaris: case report. Turk Neurosurg. 2006; 16:194-196.

27. Welling LC, Zanellato $C$, Tessari M, et al. Hemangioblastoma of the conus medullaris. Br J Neurosurg. 2012;26(2):296-297.

28. Imagama S, Ito Z, Wakao N, et al. Differentiation of localization of spinal hemangioblastomas based on imaging and pathological findings. Eur Spine J. 2011;20(8):1377-1384.

29. Imagama S, Ito Z, Ando K, et al. Rapid worsening of symptoms and high cell proliferative activity in intra- and extramedullary spinal hemangioblastoma: a need for earlier surgery. Global Spine J. 2017;7(1):6-13.

30. Kanno H, Yamamoto I, Nishikawa R, et al. Spinal cord hemangioblastomas in von Hippel-Lindau disease. Spinal Cord. 2009;47(6): 447-452.

31. Feletti A, Anglani M, Scarpa B, et al. Von Hippel-Lindau disease: an evaluation of natural history and functional disability. Neuro Oncol. 2016;18(7):1011-1020.

32. Kim TY, Yoon DH, Shin HC, et al. Spinal cord hemangioblastomas in von Hippel-Lindau disease: management of asymptomatic and symptomatic tumors. Yonsei Med J. 2012;53(6):1073-1080. 
33. Sun HI, Özduman K, Usseli MI, et al. Sporadic spinal hemangioblastomas can be effectively treated by microsurgery alone. World Neurosurg. 2014;82(5):836-847.

34. Bickle I, Wein S. Spinal hemangioblastoma. Accessed January 20, 2021. https://radiopaediaorg/articles/spinal-haemangioblastoma? lang=us

35. Beall DP, Googe DJ, Emery RL, et al. Extramedullary intradural spinal tumors: a pictorial review. Curr Probl Diagn Radiol. 2007;36(5): 185-198.

\section{Disclosures}

The authors report no conflict of interest concerning the materials or methods used in this study or the findings specified in this paper.

\section{Author Contributions}

Conception and design: CB Shields, LBE Shields, Harpring. Acquisition of data: CB Shields, LBE Shields, Harpring, Highfield. Analysis and interpretation of data: CB Shields, LBE Shields, Harpring, Highfield.
Drafting the article: LBE Shields. Critically revising the article: CB Shields, LBE Shields, Harpring, Highfield, Zhang. Reviewed submitted version of manuscript: CB Shields, LBE Shields, Harpring, Highfield, Zhang. Approved the final version: CB Shields, LBE Shields. Administrative/technical/material support: CB Shields. Study supervision: CB Shields.

\section{Correspondence}

Christopher B. Shields: Norton Neuroscience Institute, Norton Healthcare, Louisville, KY. cbshields1@gmail.com. 